\title{
Application of Bayes' theorem to the diagnosis of ankylosing spondylitis from radioisotope bone scans
}

\author{
B L DIFFEY, ${ }^{1}$ B PAL ${ }^{2}$ C J GIBSON, C B CLAYTON ${ }^{3}$ AND I D GRIFFITHS \\ From the ${ }^{1}$ Department of Medical Physics, Dryburn Hospital, Durham; the ${ }^{2}$ Department of Rheumatology, \\ Royal Victoria Infirmary, Newcastle upon Tyne; and the ${ }^{3}$ Department of Medical Physics, Royal Victoria \\ Infirmary, Newcastle upon Tyne
}

SUMMARY The ratio of the uptake of radioactivity in each sacroiliac joint to the uptake in the sacrum has been measured in 57 patients with early ankylosing spondylitis and in 51 control subjects. The distribution of ratios of uptake obtained in each of these two groups shows appreciable overlap, and it is shown that the specification of a 'normal range' in this sort of situation can be misleading in the interpretation of the uptake ratio obtained in a given subject. An alternative approach described here is to use Bayes' theorem, which combines a probability based on the numerical value of the measured ratio with the pretest clinical impression about the likelihood of ankylosing spondylitis to yield a post-test probability of the presence of the disease.

The diagnosis of ankylosing spondylitis (AS) in the presence of classical clinical and radiological features presents no difficulty. The diagnosis of early disease is more problematical. Clinical and radiological assessment has concentrated on the sacroiliac (SI) joints because these are involved consistently at the earliest stages. Unfortunately clinical tests for sacroiliac involvement are insensitive and lack specificity. ${ }^{1}$ Radiological changes may not be present and when demonstrable in the earlier stages are subject to considerable interobserver variation in interpretation. ${ }^{2}{ }^{3}$

Quantitative radioisotope imaging of the sacroiliac joints was first described by Russell et al. ${ }^{4}$ The principle of the technique is to compare the uptake of radioactivity in each sacroiliac joint with the uptake in the sacrum and to derive a quantitative sacroiliac/sacrum (SI/S) ratio of uptake. Although many centres have found the technique useful, ${ }^{4}$ others have found the overlap between normal and disease groups too great to allow useful clinical interpretation. $^{6} 7$

We have assessed the value of sacroiliac imaging in the diagnosis of early ankylosing spondylitis and interpreted the results with Bayes' theorem. Bayes' theorem allows data to be interpreted in the light of the pretest clinical diagnosis, rather than by arbitary reference to a ubiquitous normal range.

Accepted for publication 27 March 1985

Correspondence to Dr B L Diffey, Medical Physics Department, Dryburn Hospital, Durham DH1 5TW.

\section{Patients and methods}

PATIENTS AND CONTROL SUBJECTS

Fifty-seven patients with a clinical diagnosis of early ankylosing spondylitis were studied. All had low back pain, morning stiffness, and possessed HLAB27. Pelvic radiographs were graded for sacroiliitis on a five-point scale, ${ }^{8}$ as follows: $0=$ normal; $1=$ doubtful; 2 =unequivocal sacroiliitis characterised mostly by marginal sclerosis and minimal erosions without clear alteration of the joint width; $3=$ preponderance of erosions, widening and narrowing of the joint width with partial ankylosis; $4=$ total ankylosis. Seventeen patients had grade 0 , 22 had grade 1 , and 18 had grade 2 changes. No patient had grade 3 or 4 changes.

Sacroiliac scans were also performed on 51

Table 1 Number of subjects in both groups according to sex and age

\begin{tabular}{llc}
\hline Variable & \multicolumn{2}{l}{ Group } \\
\cline { 2 - 3 } & Control & Early \\
& & \\
\hline Number of subjects & 51 & 57 \\
Sex & & \\
$\quad$ Male & 37 & 46 \\
Female & 14 & 11 \\
Age (years) & & \\
$\quad$ Mean & 34 & 30 \\
Range & $17-60$ & $18-60$ \\
\hline
\end{tabular}


control subjects; this group comprised 14 subjects with no rheumatological complaint and 37 subjects with mechanical lower back pain. Demographic details on the subjects studied are given in Table 1 .

\section{SACROILIAC IMAGING}

Subjects were injected intravenously with $370 \mathrm{MBq}$ of ${ }^{99 \mathrm{~m}} \mathrm{Tc}$ methylene disphosphonate and two to three hours later the pelvis was imaged using a gammacamera. The sacroiliac/sacrum ratio of uptake was determined for the mid to lower region of each sacroiliac joint.

\section{Results}

The SI/S ratios for the control and early AS groups: are plotted in Fig. 1. The horizontal broken line iros Fig. 1 represents the upper limit of the normat range', defined as the mean SI/S ratio (1.22) pluso two standard deviations $(1 \mathrm{SD}=0 \cdot 22)$. It may be seers that a considerable proportion $(40 \%)$ of the earl AS patients lay within this normal range. Frequency histograms of the SI/S ratios are plotted in Fig. 2S

Inspection of the frequency histograms in Fig. $P$ suggests that the SI/S ratios for both the normal and

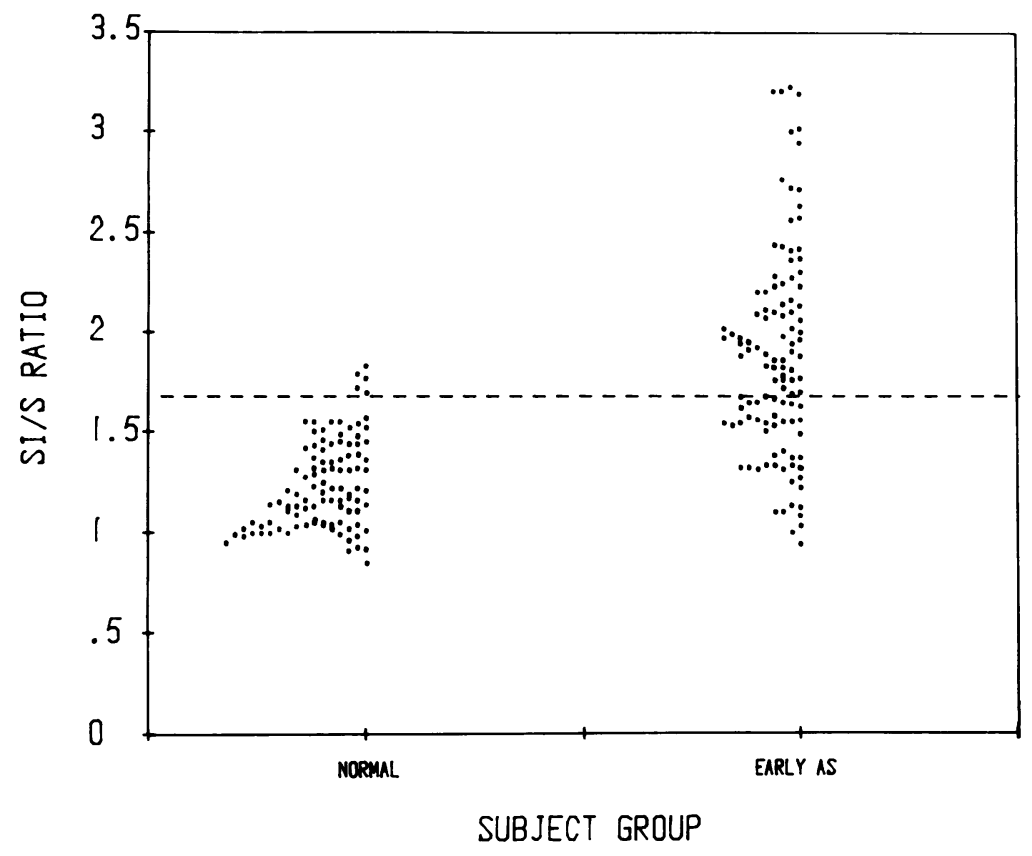

Fig. 2 The frequency histogram of SI/S ratios in control and early AS subjects. The smooth curves follow a lognormal distribution.
Fig. 1 The sacroiliac/sacrum (SI/S) uptake ratios in control subjects and those with early ankylosing spondylitis (AS).
MORUL

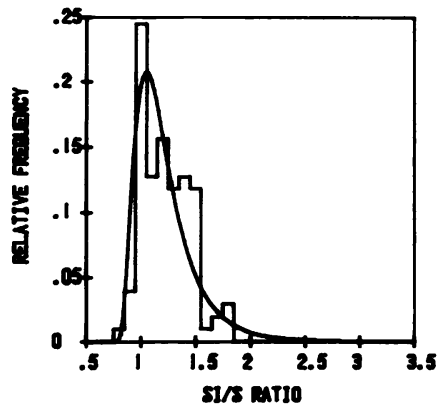

EARLY ANKYLOSING SPONDYLITIS

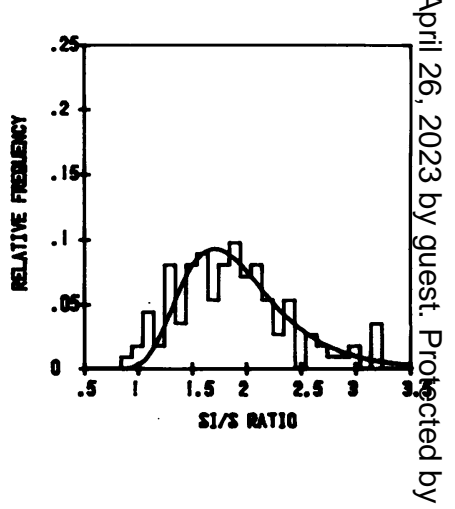


the early AS subjects may be modelled by lognormal distributions. A non-linear iterative least squares technique was applied to the two sets of data in order to fit these two functions.

The smooth curves drawn through the frequency histograms in Fig. 2 represent the likelihood of a given SI/S ratio in either normal subjects or those with early AS. For both groups of subjects the likelihood, or probability density function (p), of a given SI/S ratio $(r)$ is expressed as:

$$
\mathrm{p}=\frac{\exp \left(\mu-\sigma^{2} / 2\right)}{\sigma \sqrt{ } 2 \pi} \times \exp \left\{-\left[\ln \left(\mathrm{r}-\mathrm{r}_{0}\right)+\mu\right]^{2} / 2 \sigma^{2}\right\}
$$

The numerical values of $\mu, \sigma$, and $r_{0}$ for the two groups of subjects are given in Table 2 .

If a radioisotope bone scan is performed on a patient with suspected early AS and a SI/S ratio (r) is obtained, what can be inferred from the result? Let the prior (or pretest) probability of the patient having early $A S$ be $A(A \leqslant 1)$. If only two possible disease states are considered, that is either early AS or normal, then 1-A is the prior probability that the patient is 'normal'. (The patient may of course have some other medical problem unassociated with the ability of the SI joints to take up radioactivity.) A new probability (P) (often called a 'posterior' or 'post-test probability') can be calculated by combining the prior probability (A) with the bone scan findings as follows:

$$
P=\frac{A p_{a}}{(1-A) p_{n}+A p_{a}}
$$

where $p_{n}$ and $p_{a}$ are the likelihoods for normal and early AS subjects respectively. The post-test probability (P) is displayed in Fig. 3 as a function of the pretest probability (A) for different SI/S ratios.

\section{Discussion}

Pathognomonic diagnostic tests are uncommon in rheumatology. The majority of investigations, such as rheumatoid factor, serum uric acid, erosive changes, etc., are used to obtain corroborative evidence for or against the pretest clinical diagnosis.

Table 2 Numerical values of the parameters used to model the frequency distributions (equation 1)

\begin{tabular}{llc}
\hline Parameter & Group & \\
\cline { 2 - 3 } & Normal & Early AS \\
\hline$\mu$ & 1.2 & -0.15 \\
$\sigma$ & 0.548 & 0.354 \\
$\mathrm{r}_{0}$ & 0.75 & 0.55 \\
\hline
\end{tabular}

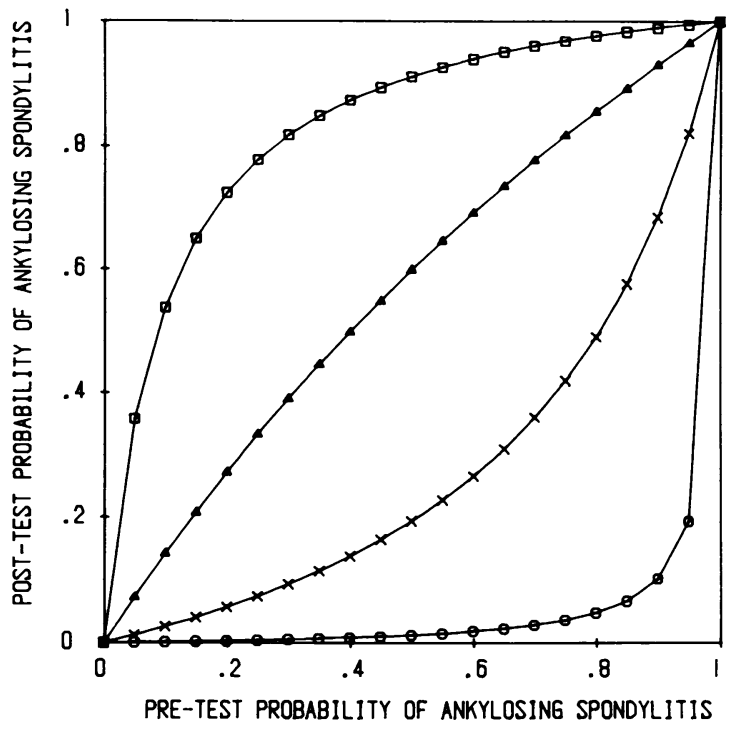

Fig. 3 The post-test probability of early ankylosing spondylitis plotted against the pretest probability for different SI/S uptake ratios: $0-0, S I / S=1 \cdot 0 ; \times \longrightarrow \times$, $S I / S=1 \cdot 25 ; \triangle \longrightarrow \triangle, S I / S=1 \cdot 5 ; \square \longrightarrow \square, S I / S=2 \cdot 0$.

The lack of absolute sensitivity and specificity does not imply that these tests are of no diagnostic value. However, a test is only useful if the pretest diagnosis is influenced by the outcome of the investigation. Bayes' theorem provides a useful mathematical technique for quantifying the influence of a test by comparing the pretest and post-test probabilities of disease for various outcomes.

It is clear from the results of this and previous studies, that sacroilac imaging, like so many other rheumatological investigations, does not offer absolute diagnostic sensitivity or specificity. However, the results suggest that the postinvestigation diagnosis is sufficiently influenced by the test to justify its retention as a 'clinically useful' investigation. For example, a pretest probability of ankylosing spondylitis of $30 \%$ would increase to a post-test diagnostic probability of $80 \%$ if the sacroiliac/sacrum ratio were 2.0 ; whereas a pretest diagnostic probability of $70 \%$ would fall post-test to $35 \%$ if the SI/S ratio were $1 \cdot 25$.

Khan and Khan ${ }^{9}$ have applied Bayes' theorem to the diagnostic significance of HLA-B27 in both ankylosing spondylitis and Reiter's syndrome. Direct comparison of the respective influences of HLA typing and sacroiliac radioisotope imaging is not possible, because HLA typing shows either the presence or absence of a cell surface antigen, whereas radioisotope imaging provides a quantitative result. In broad terms, however, our results 
would suggest that the finding of a SI/S ratio of 2 influenced pre- to post-test probabilities to a degree similar to that detected by Khan and Khan ${ }^{\overline{9}}$ for the presence of HLA-B27. A ratio of 1.25 affects preto post-test diagnosis in a similar fashion to the absence of HLA-B27.

In a clinical situation the physician does not depend upon isolated data in order to achieve a reasonable diagnosis. The early diagnosis of ankylosing spondylitis is no exception. A variety of clinical, laboratory, and radiological data is critical. We feel that radioisotope imaging of the sacroiliac joints may be valuable when radiographs are equivocal. The interpretation of the data must allow for clinical pretest 'suspicion'. Bayes' theorem permits a clinically more meaningful assessment of the data.

\footnotetext{
References

1 Blower P W. Griffin A J. Clinical sacroiliac tests in ankylosing spondylitis and other causes of low back pain - two studies. Ann Rheum Dis 1984; 43: 192-5.

2 Macrae J F, Haslock D I. Wright V. Grading of films for
}

sacroiliitis in population studies. Ann Rheum Dis 1971; 30. 58-66.

3 Resnick D, Niwayama G, Georgen T G. Comparison of radiographic abnormalities of the sacroiliac joints in degenerad tive discase and ankylosing spondylitis. Am J Roentgenol $197 \not{p q}$ 128: $189-96$.

4 Russell A S, Lentle B C. Percy J S. Investigation of sacroilif disease: comparative evaluation of radiological and radion clide techniques. J Rheumatol 1975; 2: 45-51.

5 Namey T C. McIntyre J. Bose M, et al. Nucleographic studies axial spondyloarthritides. I. Quantitative sacroiliac scintigrapty in early HLA-B27 associated sacroiliitis Arthritis Rheum 197\% 20: $1058-64$.

6 Dequeker J. Goddecris T, Walravens M, et al. Evaluation of sacroiliitis: comparison of radiological and radionuclide tec niques. Radiology 1978; 128: 687-9.

7 Snaith M L. Galvin S E J, Short M D. The value of quantitati radioisotope scanning in the differential diagnosis of low bae pain and sacroiliac disease. $J$ Rheumatol 1982; 9: 435-40.

8 Crofton J P. Report from the subcommittee on diagnostic criteria for ankylosing spondylitis. In: Bennett $\mathrm{P} \mathrm{H}$, Woọ $\mathrm{P} \mathrm{H} \mathrm{N}$, eds. Population studies of the rheumatic diseases Amsterdam: Excerpta Medica, 1968: 314-6. (Internationa Congress Series No. 148).

9 Khan M A. Khan M K. Diagnostic value of HLA-B27 testing in ankylosing spondylitis and Reiter's syndrome. Ann Intern Med 1982; 96: 70-6.

\section{Book reviews}

Clinics in Rheumatic Diseases. Anti-rheumatic Drugs III. By E C Huskisson. Pp. 432. £12.50. Saunders: London. 1984.

This volume of the 'Clinics' lives up to the usual high standards of production. The gloomy foreword (not to mention the grim passport photograph of the Editor) should not deter the reader for there is much of great value. The chapters fall into two groups - those describing specific drugs and those on more general subjects. Two of the drugs individually described (auranofin and isoxicam) have not yet arrived in the British marketplace, and so their sections seem to be a bit of a waste. Indeed I was not convinced from what I read that auranofin will ever find a place among the current second-line drugs. I suppose that details of animal studies have to be included for completeness, but I found them to be of no interest or relevance. and the tables of acetic acid writhing tests and so forth are positively horrid.

The general chapters are good if rather dry. I liked particularly the section on drug interactions, perhaps because it was unfamiliar ground, but would recommend the osteoarthritis and septic arthritis chapters as standard reference texts for doctors and students alike. The Editor's own chapter on choosing non-steroidal anti-inflammatory drugs has suddenly developed a serious political message; for when he says 'It would be nice to suggest that he (the rheumatologist) should get to know a few good drugs and ignore the others but this would deny some patients their optimal treatment' I am sure he speaks for the specialty and whither then the limited list we all half expect the government to try and impose? Copies of the book to all MPs if it does!
The best bit, however, is kept until last. Tom Bittre's discussion of combination therapy in rheumatoid artion is provocative and in contrast with the rest of the bo highly entertaining. Would that more scientific write⿳亠口冋 would (or could) write such exciting stuff. It was thes chapter that made me think the most.

ANDREW BAM

The Practical Treatment of Backache and Sciaticå By J Barrett and D N Golding. Pp. 106. £15.9 MTP Press: Lancaster. 1984.

There is a minor epidemic of compact books dealing wi菊 backache. The collaboration of a rheumatologist know for his concise writing and an orthopaedic physician is attractive sounding pairing to produce a book principalg aimed at the general practitioner. How does it fare?

Many of the ideas are good. The subject headings are practical, and the flow charts are condensed guides $\circledast$ management.

Unfortunately, I found the literary style difficult to rea and my interest fell off seriously at about the half-way mark. In addition, it is clear that the proof readers had an off day allowing spelling errors and inconsistencies - fơ example 'gas' in the disc on $p .17$ becomes 'air' by p.28. ThE headings are quite neatly presented, but the photograples are visually unattractive.

Although the text lacks the critical and stimulation qualities required by specialists, it is a useful guide foof generalists wishing to acquaint themselves with some of the mystique and practices in this field. The description 'coof book' used in the foreword is apt.

JOHN A MATHEW 